For mat i on and assi gnment of si I ver def ect centres in phosphate gl ass i nduced by femt osecond I aser pul ses

\begin{tabular}{|l|l|}
\hline 著者 & $\begin{array}{l}\text { Zheng Wang, Kur obor i Toshi o, M yanot o Yuka, } \\
\text { Nant o H dehi t o, Yamant o Takayoshi }\end{array}$ \\
\hline $\begin{array}{l}\text { j our nal or } \\
\text { publ i cat i on t i t l e }\end{array}$ & Radi at i on Measur ement s \\
\hline vol une & 46 \\
\hline number & 12 \\
\hline page r ange & $1402-1405$ \\
\hline year & 2011- 12-01 \\
\hline URL & ht t p: //hdl . handl e. net /2297/30103 \\
\hline
\end{tabular}




\title{
Formation and assignment of silver defect centres in phosphate glass induced by femtosecond laser pulses
}

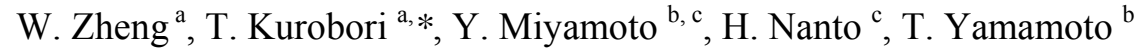 \\ ${ }^{a}$ Graduate School of Natural Science and Technology, Kanazawa University, Kakuma-machi, Kanazawa, \\ Ishikawa 920-1192, Japan \\ b Oarai Research Center, Chiyoda Technol Corporation, 3681 Narita-cho, Oarai, Ibaraki 311-1313, Japan \\ ${ }^{\mathrm{c}}$ Advanced Material Science R\& D Center, Kanazawa Institute of Technology, 7-1 Oogigaoka, Nonoichi-machi, \\ Ishikawa 921-8812, Japan
}

\begin{abstract}
We have investigated the formation and assignment of silver defect centres such as $\mathrm{Ag}^{0}$, $\mathrm{Ag}^{2+}$ and other molecular silver species induced by femtosecond (fs) laser pulse irradiation. In particular, direct precipitation of silver nanoparticles without heat treatment was demonstrated to clarify the formation kinetics of silver defect centres in a radiophotoluminescent phosphate glass by $250 \mathrm{kHz}$ high repetition rate fs laser pulses. Comparison using X-ray- and fs laser-irradiation methods is also presented.
\end{abstract}

PACS: 78.60.-b; 81.05.Kf; 78.40. Pg; 78.70.En; 78.70.Dm

Keywords: Radiophotoluminescence (RPL), Glass dosimeter, Silver defect species, Femtosecond laser

${ }^{*}$ Corresponding author. fax: +81-76- 234-4132

*E-mail address: laser@kenroku.kanazawa-u.ac.jp (T. Kurobori) 


\section{Introduction}

Recent advances in high-intensity femtosecond (fs) laser pulses have made it possible to fabricate small noble metal particles such as gold and silver atoms embedded in glasses (Watanabe et al., 2001; Zhao et al., 2004; Shimotsuma et al., 2005) as well as encode various functional microstructures inside transparent materials (Kawamura et al., 2004; Kurobori et al., 2005; Kurobori et al., 2007). As far as silver-doped phosphate glass, Watanabe et al. (2001) demonstrated a photosensitivity in soda-alumina-phosphate glass doped with $\mathrm{Ag}^{+}$upon exposure to ultraviolet (UV) fs laser pulses and found the formation of colour centres such as $\mathrm{Ag}^{0}$ and $\mathrm{Ag}^{2+}$ in the glass. Zhao et al. (2004) investigated the precipitation and dissolution of nanoparticles in $\mathrm{Ag}^{+}$-doped phosphate glass by irradiation with a near-infrared (IR) $800 \mathrm{~nm}$ fs laser pulses and further annealing at various temperatures. Recently, intense fs laser pulses with high-peak power densities $\left(\sim 100 \mathrm{TW} / \mathrm{cm}^{2}\right)$ and high repetition rates $(>200 \mathrm{kHz})$ have enabled direct precipitation of silver nanoparticles in silver-activated silicate glass without heat treatment (Ma et al., 2009).

As one of other practical applications of silver-doped phosphate glass (the sample denoted with "PG:Ag"), after PG:Ag is exposed to ionising radiation such as beta-, gamma- and X-rays, it emits an intense radiation-induced orange luminescence by UV excitation, which is called radiophotoluminescence (RPL). Such a dose-dependent RPL phenomenon in PG:Ag 
has been widely applied to a ideal personal and environmental monitoring dosimeter (Hsu et al., 2006; Ranogajec-Komor et al., 2008; Chiyoda Technol Corporation, 2007).

Recently, we have systematically investigated the assignments and optical properties of X-ray-induced silver-related species of PG:Ag by means of various optical measurements such as RPL decay curve analysis, peak fitting analysis and heat treatments (Kurobori et al., 2010; Zheng and Kurobori, 2011). It was established from these results that the decomposed six Gaussian bands induced by X-ray irradiation in PG:Ag were, in turn, attributed to $\mathrm{Ag}^{+}$, $\mathrm{Ag}_{3}{ }^{+}$or $\mathrm{Ag}_{3}{ }^{2+}, \mathrm{Ag}_{2}{ }^{+}, \mathrm{Ag}^{2+}, \mathrm{Ag}^{0}$ and hole-trap centres, respectively. In addition, some similar spectral studies of the silver-related species created after different irradiation have also been reported to clearly attribute these $\operatorname{Ag}_{\mathrm{m}}{ }^{\mathrm{x}}$ centres in various glasses (Maurel et al., 2009; Jiménez et al., 2009; Miyamoto et al., 2010).

This paper examines the formation and assignment of silver defect centres such as $\mathrm{Ag}^{0}$, $\mathrm{Ag}^{2+}$ and other molecular silver species induced by fs laser pulse irradiation. In particular, direct precipitation of silver nanoparticles in $\mathrm{PG}: \mathrm{Ag}$ without heat treatment was demonstrated for the first time to clarify the formation kinetics and give an additional evidence of silver-related colour centres in a RPL glass by $250 \mathrm{kHz}$ high repetition rate fs laser pulses. Comparison using X-ray- and fs laser-irradiation methods is also presented.

\section{Experimental details}


A commercially available GD-450 dosimeter (AGC Techno Glass Co. Ltd.) was used as the radiophotoluminescent PG:Ag. Samples were cut from the original glass dosimeter plate to a size of approximately $10 \times 7 \times 1 \mathrm{~mm}^{3}$. The weight composition of the GD-450 dosimeter was $31.55 \% \mathrm{P}, 51.16 \% \mathrm{O}, 6.12 \% \mathrm{Al}, 11.00 \% \mathrm{Na}$ and $0.17 \% \mathrm{Ag}$. An additional sample without Ag (the sample denoted with "undoped PG") was used as a reference sample.

All samples were coloured by irradiation from an X-ray unit with a copper target operated at $30 \mathrm{kV}$ and $20 \mathrm{~mA}$. In this work, the samples were irradiated by doses of $4.90 \mathrm{~Gy}$ and 24.5 Gy. Absorption, excitation and emission measurements were performed at room temperature using a Hitachi U-2010 UV-vis and an F-2500 fluorescence spectrophotometer.

For the direct photo-induced reduction from $\mathrm{Ag}^{+}$ions to $\mathrm{Ag}^{0}$ centres in $\mathrm{PG}: \mathrm{Ag}$, this work used a regeneratively amplified 800-nm Ti:sapphire laser (Coherent, Mira and RegA) that emitted $80-\mathrm{fs}, 250-\mathrm{kHz}$ mode-locked pulses. The fs laser pulses were focused using a $20 \times$ objective lens $(\mathrm{NA}=0.45)$ to a depth of $250 \mu \mathrm{m}$ beneath the sample surface with the help of a computer-controlled 3D $X-Y-Z$ stage at a speed of $1 \mathrm{~mm} / \mathrm{s}$ and $100 \mu \mathrm{m} / \mathrm{s}$. The pulse energy ranged from 2 to $3 \mu \mathrm{J} /$ pulse and the spot diameter was approximately $2 \mu \mathrm{m}$.

The numbers of successive pulses at the focal points were $2.5 \times 10^{5}$ shots in $1 \mathrm{~s}$. A square $5 \times 5 \mathrm{~mm}^{2}$ area was written inside the sample line by line using the intense and high 
repetition rate fs laser pulses to measure the absorption, excitation and emission spectra of the irradiation region inside the glass sample.

\section{Results and discussion}

\subsection{Optical characteristics and peak fitting analysis}

Figs. 1 show the optical absorption spectra of (a) 1.0-mm-thick undoped PG and (b) 1.0-mm-thick PG:Ag, respectively, before and after X-ray irradiation. Prior to X-ray irradiation, both samples were colourless with an absorption edge at about $300 \mathrm{~nm}$ and then both samples were irradiated by X-rays to an absorbed dose of $24.5 \mathrm{~Gy}$ at room temperature. Fig. 1(a) shows the absorption spectrum before (dashed-and-dotted line) and after (solid line) X-ray irradiation. Moreover, the absorption spectrum was decomposed into a sum of separate Gaussian bands to characterise radiation-induced defect centres, as shown in the inset. Concerning to the radiation-induced effects in phosphate glass, Ebeling et al. (2002) investigated the assignment of X-ray-induced defects in ultra- and meta-phosphate glasses of high purity by means of band separation of the optical spectra. In our undoped PG, the absorption spectrum (Curve 1) could be decomposed into 4 separate Gaussian bands (dashed line, Curves 2-5) peaking at $206 \mathrm{~nm}(6.03 \mathrm{eV}), 224 \mathrm{~nm}(5.53 \mathrm{eV}), 273 \mathrm{~nm}(4.54 \mathrm{eV})$ and 440 $\mathrm{nm}(2.82 \mathrm{eV})$, respectively. According to Ebeling et al. (2002), the absorption bands located 
at 206 (Curve 2) and $224 \mathrm{~nm}$ (Curve 3) are ascribed to electron trapped $\mathrm{PO}_{3}$ and $\mathrm{PO}_{4}$ defect centres, respectively. Moreover, the absorption band at $273 \mathrm{~nm}$ (Curve 4) corresponds to absorption of oxygen-related hole centres of unknown structure (OHC). Broad absorption band at $440 \mathrm{~nm}$ (Curve 5), termed the phosphorus-oxygen-hole-center (POHC), is due to one or two non-bridging oxygen of a $\mathrm{PO}_{4}$ unit trapping a hole (Griscom et al., 1983).

Fig. 1(b) shows the absorption (solid line) and excitation (dashed-and-dotted line, Curves 1 and 2) and RPL spectra (solid line, Curves 3-5) of the X-ray irradiated PG:Ag under an absorbed dose of $24.5 \mathrm{~Gy}$. The absorption spectrum is obviously due to the superposition of a number of individual absorption bands corresponding to the different colour centres. Therefore, the peak fitting analysis was carried out on the basis of the strong analogy with X-ray-irradiated silver-doped sodium chloride ( $\mathrm{NaCl}: \mathrm{Ag}$ ) (Kurobori et al., 2010). The absorption spectrum could be decomposed into the sum of separate Gaussian bands (indicated by a dashed line) from "A" to "F", peaking at 225, 252, 270, 307, 354 and $424 \mathrm{~nm}$, respectively. The excitation spectra consist of two different spectra. One spectrum peaks at $308 \mathrm{~nm}$ (Curve 1) for an emission at $560 \mathrm{~nm}$ (orange), and the other peaks at 270 and $345 \mathrm{~nm}$ (Curve 2) for an emission at $450 \mathrm{~nm}$ (blue). The former corresponds to the decomposed 307 nm Gaussian band, while the latter corresponds to the decomposed 270 and $354 \mathrm{~nm}$ bands, respectively. The blue emission with some portion of the orange emission are strongly related 
to the 270 and $345 \mathrm{~nm}$ excitation bands, which is completely analogous to the blue emission of $\mathrm{NaCl}: \mathrm{Ag}$ associated with bands "B" and "C" (Kurobori et al., 2010), respectively.

\subsection{Femtosecond laser exposure}

According to our report (Kurobori et al., 2010), it was established through RPL decay curve analysis, peak fitting analysis and heat treatments that the decomposed six Gaussian bands in X-ray irradiated PG:Ag as shown in Fig. 1(b), marked as "A" to "F", were attributed to $\mathrm{Ag}^{+}, \mathrm{Ag}_{3}{ }^{+}$or $\mathrm{Ag}_{3}{ }^{2+}, \mathrm{Ag}_{2}{ }^{+}, \mathrm{Ag}^{2+}, \mathrm{Ag}^{0}$ and POHC bands, respectively.

In this work, an additional evidence to attribute the $345 \mathrm{~nm}$ band ("E" band) in X-ray irradiated PG: $\mathrm{Ag}$ to $\mathrm{Ag}^{0}$ centres was demonstrated by directly fs laser pulse irradiation. It is well-known that irradiation with fs laser pulses as well as X-rays and subsequent annealing at high temperature $(\sim 770 \mathrm{~K})$ for $10 \mathrm{~min}$ in silver-doped glasses bring about the reduction of $\mathrm{Ag}^{+}$ions to $\mathrm{Ag}^{0}$ atoms and result in the formation of plasmonic nanoparticles, as observed by means of luminescence, electron spin resonance (ESR) and transmission electron microscopy (TEM) (Zhao et al., 2004; Shimotsuma et al., 2005).

Fig. 2 shows the absorption spectra before (Curve 1) and after irradiation of X-ray (Curve 2) and fs laser pulses (Curves 3 and 4). Note that these irradiated absorption spectra show the difference in absorbance between the X-ray and fs laser irradiated- and nonirradiated-glasses. For Curves 3 and 4, the average power was 500 and $700 \mathrm{~mW}$ at scanning rates of $1 \mathrm{~mm} / \mathrm{s}$ 
and $100 \mu \mathrm{m} / \mathrm{s}$, respectively. The spot diameter was approximately $2 \mu \mathrm{m}$. The peak power density of the laser beam irradiated on the sample was estimated to be $8.0 \times 10^{14} \mathrm{~W} / \mathrm{cm}^{2}$ for Curve 3 and $1.1 \times 10^{15} \mathrm{~W} / \mathrm{cm}^{2}$ for Curve 4, respectively. For Curve 3, a peak position at 315 $\mathrm{nm}$ of the absorption band was in good agreement with that of the X-ray irradiated absorption band (Curve 2), while for Curve 4 the spectrum was dominated by an absorption band at $407 \mathrm{~nm}$ that could be ascribed to the surface plasmon resonance (SPR) of the formed silver nanoparticles (Zhao et al., 2004; Shimotsuma et al., 2005).

Note that irradiation with X-ray and high peak power density $\left(1.1 \times 10^{15} \mathrm{~W} / \mathrm{cm}^{2}\right)$ fs laser pulses yields different absorption peak wavelengths of the $\mathrm{Ag}^{0}$ centres as described above: the former is $345 \mathrm{~nm}$ and the latter is $407 \mathrm{~nm}$. One of the reasons for this difference is that when fs laser pulses are focused inside the sample at a high repetition rate over $250 \mathrm{kHz}$, the temperature at the focal point increases to as high as several thousand Kelvin (Sakakura et al., 2008), a much higher temperature than that reached in normal heat treatment. As a result, highly successive fs laser pulses and a slow scanning rate caused cumulative heating around the focal point. Increasing the temperature greatly increased the average size of nanoparticles formed by fs laser irradiation, resulting in a red-shift of the peak wavelength. Moreover, Ma et al. (2009) reported that the light intensity in the focus of the beam on the order of $10^{15}$ $\mathrm{W} / \mathrm{cm}^{2}$ was high enough to generate multi-photon ionisation in the glass matrix, and the heat 
accumulated by the $250-\mathrm{kHz}$ fs laser resulted in the subsequent $\mathrm{Ag}$ nanoparticles growth process.

It was found from the above results that the $345 \mathrm{~nm}$ band corresponding to the decomposed "E" band was identifiable as the tapped electron $\mathrm{Ag}^{0}$ centres (reaction: $\mathrm{Ag}^{+}+\mathrm{e}^{-}$ $\rightarrow \mathrm{Ag}^{0}$ ) due to almost overlap between the "E" and SPR band. In addition, the $270 \mathrm{~nm}$ band corresponding to the decomposed " $\mathrm{C}$ " band also increases in intensity after high intensity (1.1 $\times 10^{15} \mathrm{~W} / \mathrm{cm}^{2}$ ) fs laser pulses, therefore the "C" band was identifiable as the $\mathrm{Ag}_{2}{ }^{+}$centres (reaction: $\mathrm{Ag}^{+}+\mathrm{Ag}^{0} \rightarrow \mathrm{Ag}_{2}{ }^{+}$). As increasing the $\mathrm{Ag}^{0}$ centres, then the $\mathrm{Ag}_{2}{ }^{+}$band with coupling to $\mathrm{Ag}^{0}$ centres also increases.

On the other hand, the $310 \mathrm{~nm}$ band corresponding to the decomposed " $\mathrm{D}$ " band was attributed to the trapped hole $\mathrm{Ag}^{2+}$ centres (reaction: $\mathrm{Ag}^{+}+\mathrm{h}^{+} \rightarrow \mathrm{Ag}^{2+}$ ). In the case of PG:Ag, the holes are captured by $\mathrm{PO}_{4}$ tetrahedron at the beginning of the migration and then the holes come to produce the $\mathrm{Ag}^{2+}$ centres due to interaction with $\mathrm{Ag}^{+}$ion by the time passing. As a result, metallic nanoparticles $\left(\mathrm{Ag}^{0}\right.$ centres) can form and grow quickly under elevated temperatures at the beginning stage after fs laser irradiation, while the $\mathrm{Ag}^{2+}$ centres need long elapsed time to form. A prominent decrease in intensity around " $\mathrm{D}$ " band may be considered to reflect the above explanation.

Fig. 3 shows the excitation and emission spectra of high intensity $\left(1.1 \times 10^{15} \mathrm{~W} / \mathrm{cm}^{2}\right) \mathrm{fs}$ laser irradiated PG:Ag. Excitation spectra were detected at 450 (blue RPL) and $570 \mathrm{~nm}$ 
(orange RPL) and emission spectra were excited at $310\left(\mathrm{Ag}^{2+}\right.$ band), 360 ( $\mathrm{Ag}^{0}$ band) and 407 nm (SPR, Ag nanoparticles), respectively. Note that orange or blue emission for an excitation at $407 \mathrm{~nm}$ could not be observed, which give an additional evidence for the band assignment to silver nanoparticles. Moreover, for the excitation spectra detected at $450 \mathrm{~nm}$, photoluminescence (PL) peaking at $302 \mathrm{~nm}$ (Kurobori et al., 2010) excited by the $\mathrm{Ag}^{+}$band at $240 \mathrm{~nm}$ becoms predominant and thus a shoulder part of the PL completely overlaps a blue RPL at $450 \mathrm{~nm}$. In addition, shorter wavelength regions of the excitation spectrum detected at $570 \mathrm{~nm}$ are not stable as shown in Fig. 3, which may reflect the characteristics of the induced $\mathrm{Ag}_{2}{ }^{+}\left(\mathrm{Ag}^{+}+\mathrm{Ag}^{0} \rightarrow \mathrm{Ag}_{2}{ }^{+}\right)$centres. On the other hand, in the case of low intensity fs laser irradiated PG:Ag, both emission and excitation spectra were very similar to those of X-ray irradiation.

\section{Conclusions}

In summary, we have investigated the formation and assignment of silver defect centres, in particular, $\mathrm{Ag}^{0}, \mathrm{Ag}^{2+}$ and $\mathrm{Ag}_{2}{ }^{+}$species induced by high- and low-intensity fs laser pulse irradiation. Direct precipitation of silver nanoparticles in a silver-activated phosphate glass without heat treatment was demonstrated to clarify the origin of silver defect centres by 250 $\mathrm{kHz}$ high repetition rate fs laser pulses. The intensity threshold of fs irradiated region for direct formation of surface plasmonic Ag nanoparticles was the order of $10^{15} \mathrm{~W} / \mathrm{cm}^{2}$. 
However, more detailed information is needed for a satisfactory explanation of the different glass matrix structure between the $\mathrm{Ag}^{0}$ centres at $450 \mathrm{~nm}$ induced by X-ray irradiation and SPR at $407 \mathrm{~nm}$ induced by high intensity fs laser irradiation.

\section{Acknowledgements}

We would like to thank Dr. M. Sakakura, Dr. Y. Shimotsuma, Prof. K. Miura and Prof.

K. Hirao at Kyoto University for their contributions to the femtosecond laser experiments. 


\section{Figure captions}

Fig. 1 (a) Absorption spectrum before (dashed-and-dotted line) and after (solid line) X-ray irradiation with a dose of 24.5 Gy. Irradiation induced band was decomposed into a sum of separate Gaussian bands (Curves 2-5) as shown in the inset. (b) Absorption, excitation and RPL spectra of PG:Ag after X-ray irradiation with a dose of 24.5 Gy. Irradiation induced band was decomposed into six Gaussian bands (marked as A to F, dashed lines). Excitation spectra were detected at $560 \mathrm{~nm}$ (Curve 1) and $450 \mathrm{~nm}$ (Curve 2). RPL spectra were excited at $310 \mathrm{~nm}$ (Curve 3), $270 \mathrm{~nm}$ (Curve 4) and 340 nm (Curve 5).

Fig. 2 Absorption spectra before (Curve 1) and after X-ray (Curve 2) and fs laser (Curves 3 and 4) irradiation. Curve 2 was irradiated at a dose of $4.90 \mathrm{~Gy}$. Laser intensity for Curves 3 and 4 was $8.0 \times 10^{14}$ and $1.1 \times 10^{15} \mathrm{~W} / \mathrm{cm}^{2}$, respectively. Decomposed "C", "D", and "E" bands were shown for comparison.

Fig. 3 Excitation and RPL spectra of PG:Ag after high intensity $\left(1.1 \times 10^{15} \mathrm{~W} / \mathrm{cm}^{2}\right)$ fs laser irradiation. Excitation spectra were detected at 450 and $570 \mathrm{~nm}$ and RPL spectra were excited at 310, 360 and $407 \mathrm{~nm}$, respectively. 

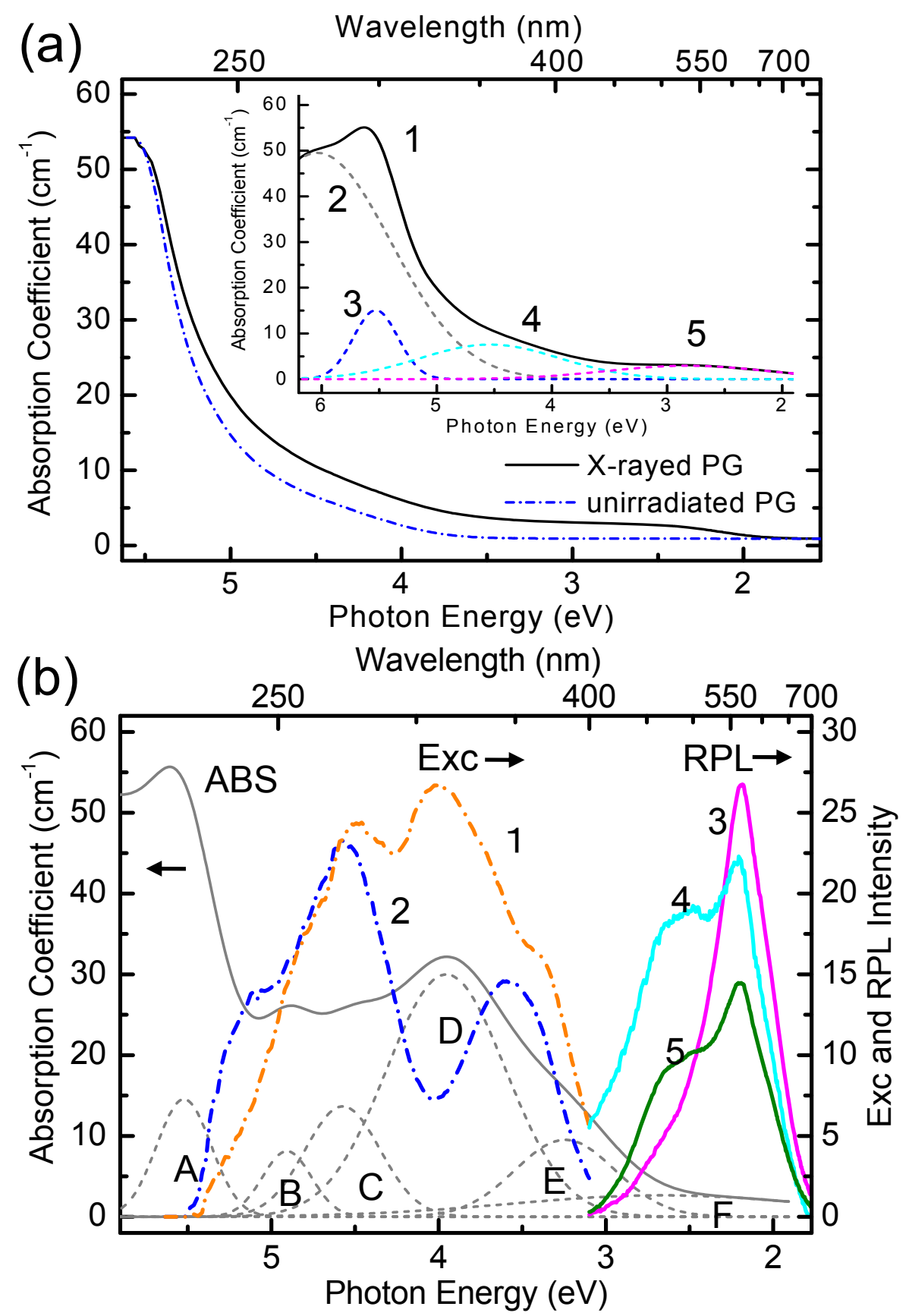

Fig.1a,b W. Zheng et al. 


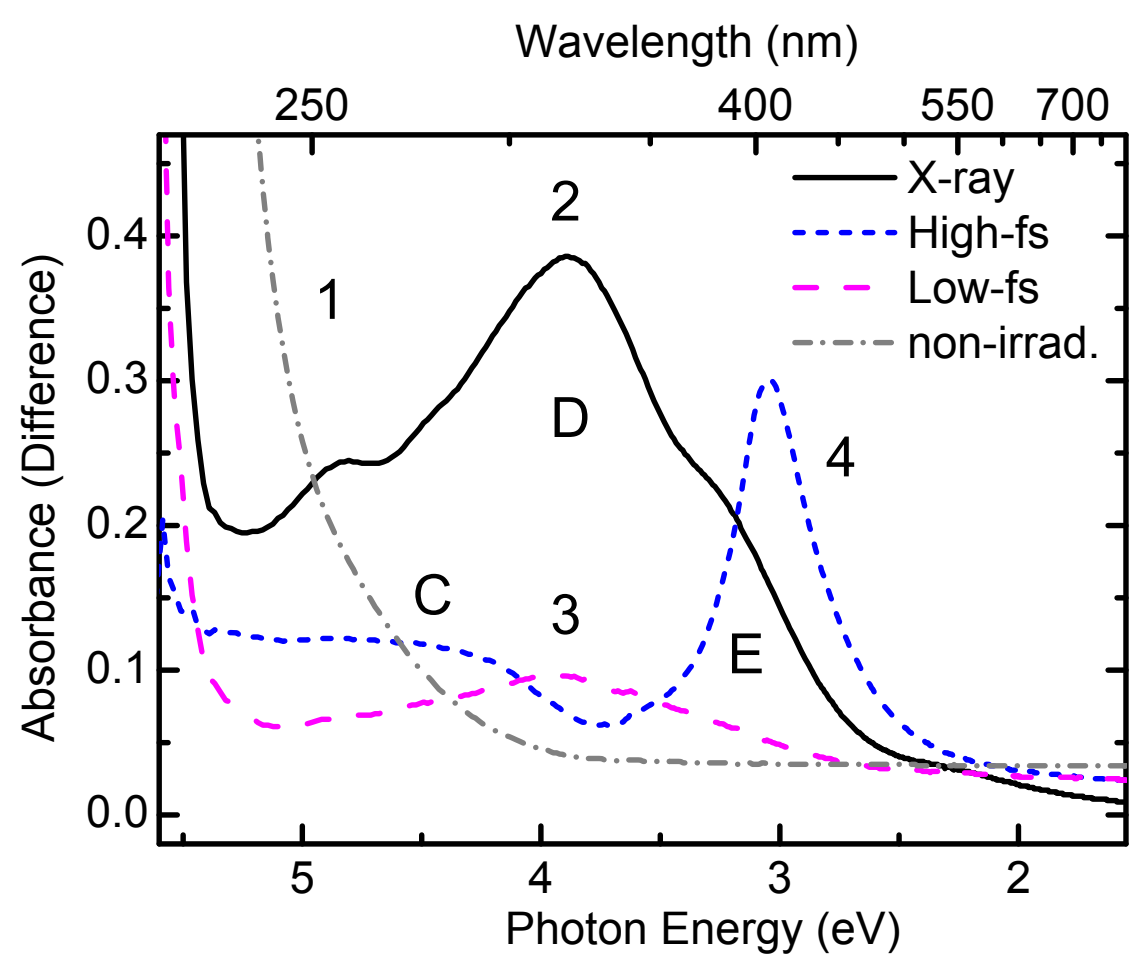

Fig.2 W. Zheng et al. 


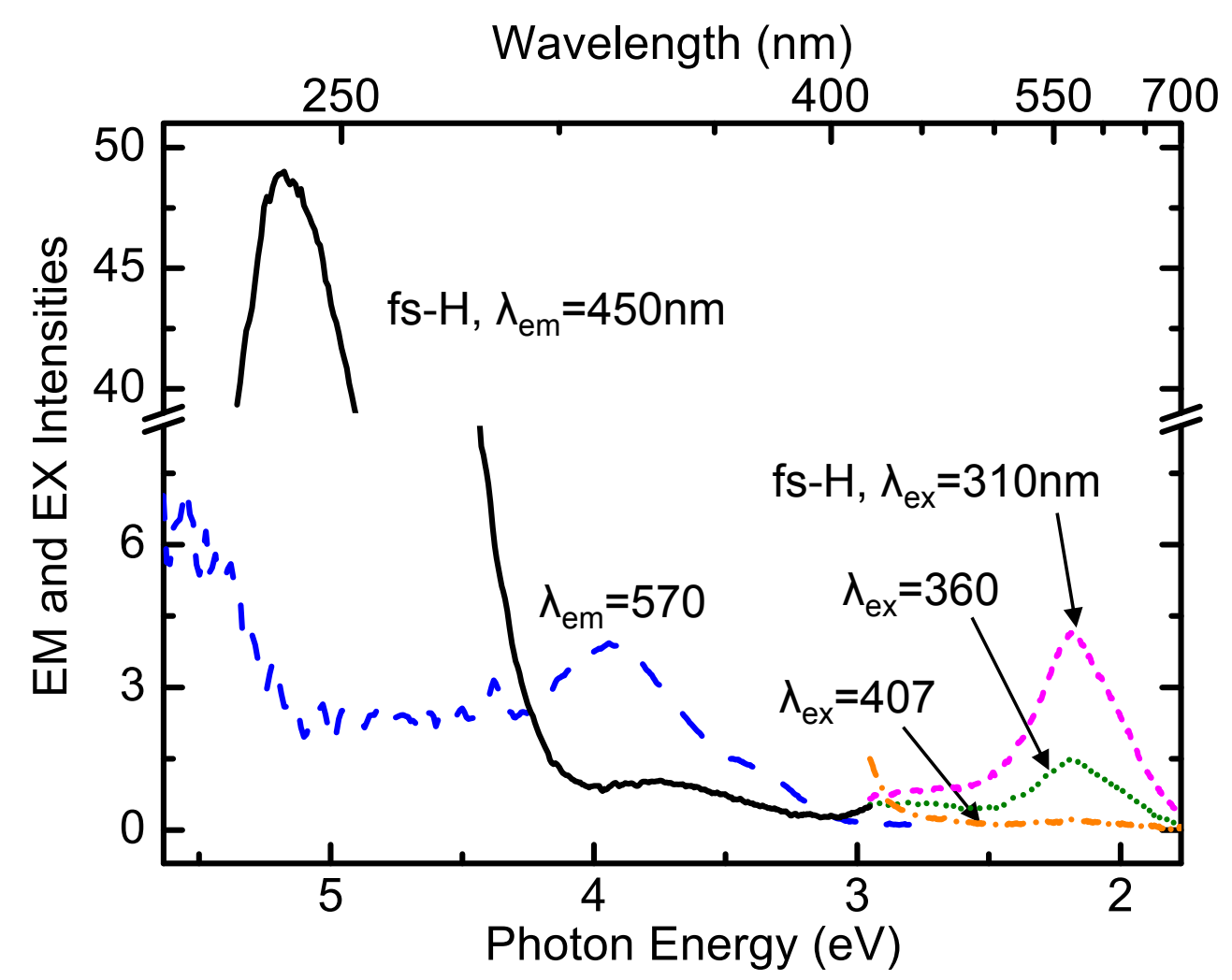

Fig.3 W. Zheng et al. 


\section{References}

Chiyoda Technol Corporation, 2007. <http://www.c-technol.co.jp/technol_eng/>

Ebeling, P., Ehrt, D., Friedrich, M., 2002. X-ray induced effects in phosphate glasses. Opt. Mater. 20 (2), 101-111.

Griscom, D. L., Friebele, E. J., Long, K. J., Flemig, J. W., 1983. Fundamental defect centers in glass:Electronspin resonance and optical absorption studies of irradiated phosphorus-doped silica glass and optical fibers. J. Appl. Phys. 54 (7), 3743-3762.

Hsu, S. M., Yeh, S. H., Lin, M. S., Chen, W. L., 2006. Comparison on characteristics of radiophotoluminescent glass dosimeters and thermoluminescent dosimeters. Radiat. Prot. Dosim. 119 (1-4), 327-331.

Jiménez, J. A., Lysenko, S., Liu, H., Fachini, E., Resto, O., Cabrera, C. R., 2009. Silver aggregates and twofold-coordinated tin centers in phosphate glass: A photoluminescence study. J. Lumin. 129 (12), 1546-1554.

Kawamura, K., Hirano, M., Kurobori, T., Takamizu, D., Kamiya, T., Hosono, H., 2004. Femtosecond-laser-encoded distributed-feedback color center laser in lithium fluoride single crystals. Appl. Phys. Lett. 84 (3), 311-313.

Kurobori, T., Yamakage, T., Hirose, Y., Kawamura, K., Hirano, M., Hosono, H., 2005. Applications of wide-band-gap materials for optoelectronic functional devices fabricated by a pair of interfering femtosecond laser pulses. Jpn. J. Appl. Phys. 44 (2), 910-913.

Kurobori, T., Sakai, T., Aoshima, S., 2007. A narrow band, green-red colour centre laser in LiF fabricated by femtosecond laser pulses. Phys. Status Solidi A 204(3), 699-705.

Kurobori, T., Zheng, W., Miyamoto, Y., Nanto, H., Yamamoto, T., 2010. The role of silver in the radiophotoluminescent properties in silver-activated phosphate glass and sodium chloride crystal. Opt. Mater. 32 (9), 1231-1236.

Ma, N. H., Ma, H. L., Zhong, M. J., Yang, J. Y., Dai, Y., Ye, G., Yue, Z. Y., Ma, G. H., Qiu, J. R., 2009. Direct precipitation of silver nanoparticles induced by a high repetition femtosecond laser. Mater. Lett. 63 (1), 151-153.

Maurel, C., Cardinal, T., Bellec, M., Canioni, L., Bousquet, B., Treguer, M., Videau, J. J., Choi, J., Richardson M., 2009. Luminescence properties of silver zinc phosphate glasses following different irradiations. J. Lumin. 129(12), 1514-1518.

Miyamoto, Y., Yamamoyo, T., Kinoshita, K., Koyama, S., Takei, Y., Nanto, H., Shimotsuma, Y., Sakakura, M., Miura, K., Hirao, K., 2010. Emission machnism of radiophotoluminescence in Ag-doped phosphate glass. Radiat. Meas. 45 (3-6), 546-549.

Ranogajec-Komor, M., Knežević, Ž., Miljanić, S., Vekić, B., 2008. Characterisation of radiophotoluminescent dosimeters for environmental monitoring. Radiat. Meas. 43 (2-6) 392-396. 
Sakakura, M., Shimizu, M., Shimotsuma, Y., Miura, K., Hirao, K., (2008). Temperature distribution and modification mechnism inside glass with heat accumulation during $250 \mathrm{kHz}$ irradiation of femtosecond laser pulses. Appl. Phys. Lett. 93(23), 231112-1-3.

Shimotsuma, Y., Hirao, K., Kazansky, P. G., Qiu, J., 2005. Three-dimensional micro- and nano-fabrication in transparent materials by femtosecond laser. Jpn. J. Appl. Phys. 44 (7A), 4735-4748.

Watanabe, Y., Namikawa, G., Onuki, T., Nishio, K., Tsuchiya, T., 2001. Photosensitivity in phosphate glass doped wiyh $\mathrm{Ag}^{+}$upon exposure to near-ultrviolet femtosecond laser pulses. Appl. Phys. Lett. 78 (15), 2125-2127.

Zhao, Q., Qiu, J., Jiang, X., Zhao, C., Zhu, C., 2004. Controllable precipitation and dissolution of silver nanoparticles in ultrafast laser pulses irradiated $\mathrm{Ag}^{+}$-doped phosphate glass. Opt. Express 12(17), 4035-4040.

Zheng, W., Kurobori, T., 2011. Assignments and optical properties of X-ray-induced colour centres in blue and orange radiophotoluminescent silver-activated glasses. J. Lumin. 131 (1) 36-40. 